\title{
폴 해리슨(Paul Harrison)의『현재의 부처님들과 직접 조우하는 삼매[般舟三昧]』에 대한 리뷰
}

이영진(금강대학교)

우선 이 책의 저자인 폴 해리슨(Paul Harrison)을 소개하자면, 호주 국립대학에서 너무나 저명한 드 용(De Jong) 교수 밑에서 박사학위 (Ph. D)를 마쳤으며, 뉴질랜드의 칸타베리 대학(Univ. of Canterbury) 의 교수직을 거쳐 현재는 스탠포드 대학(Stanford Univ.)에 있는 HCBSS(Ho Center for Buddhist Studies)의 공동책임자(co- director) 이자 교수(George Edwin Burnell Professor)를 역임하고 있다.

이미 국내에서도 여러 차례 소개되었듯이, 해리슨은 서구에서 그레 고리 쇼펜(Gregory Schopen)과 조나탄 실크(Jonathan A. Silk)와 더불 어 세계 학계에서 상당한 영향력이 있던 -현재도 영향력이 있는- 히 라카와 아키라의 대승기원설에 대해 의문을 품으며 이에 대한 대안을 제시해 왔다. 간략히 설명하자면 대승불교운동이 재가신자를 중심으 로 일어났다는 히라카와 아키라의 설에 반해, 이들은 이 운동이 출가 수행자 [일군]의 무리로부터 일어난 다양한 흐름들이 대승불교라는 하 
나의 개념아래 묶여졌을 가능성을 제시하였다.1) 이러한 학자들 중 해 리슨은 현재 우리가 접할 수 있는 가장 오래된 대승 경전, 즉 170 190 C. E.에 낙양(Luoyang)에서 활동했던 최초의 대승경전 역경승인 Lokakșema(支婁迦驖)에 의해 번역된 작업들을 통해 대승의 기원과 초기 발전과정을 재조명하려 하였다. 지금 우리가 읽고자 하는 책 또 한 'Lokakșema 프로젝트’라고 명명된 이러한 재조명 작업의 첫 번째 산물이다. 그렇지만 이러한 산물은 독립적이기보다는 1978년(b)과 1998년에 출판된 책들과 합친 시리즈 중 한 편이라고 보는 것이 적절 할 듯하다.2) 이 책의 부제 'Pratyutpanna-Buddha-Sammukhāvasthita-Samāadhi-Sütra의 티벳 버전에 대한 주해가 달린 영어 번역과 문 헌의 역사와 관련된 몇몇 부록들'이 시사해주듯이, 해리슨은 이 저술에

1) 이 셋 중 필자가 파악하고 있는 해리슨의 대승기원에 관한 논문들의 리스트는 다음과 같다.

1987, "Who Gets to Ride in the Great Vehicle? Self-image and Identity among the Followers of the Early Mahāyāna," JIABS, Vol. X, No. 1 : 67-89.

1993, "The Earliest Chinese Translations of Mahāyāna Buddhist Sūtras: Some Notes on the Works of Lokakșema," Buddhist Studies Review 10/2: 135-177. 1995, "Searching for the Origins of the Mahāyāna: What are We Looking For?" The Eastern Buddhist, New Series 28/1: pp. 48-69.

2003, "Mediums and Messages: Reflections on the Production of Mahāyāna Sūtras," Eastern Buddhist 35.1: 115-151.

2) (1) 1978(b), The Tibetan text of the Pratyutpanna-Buddha-SammukhavasthitaSamādhi-Sūtra / critically edited from the Derge, Narthang, Peking and Lhasa editions of the Tibetan Kanjur and accompanied by a Concordance and Comparative Table of Chapters of the Tibetan and Chinese version [by] Paul M. Harrison, Studia philologica Buddhica. Monograph series 1, Tokyo : Reiyukai Library. (2) 1998, The Pratyutpanna Samādhi Sūtra translated by Lokakșema: Translated from the Chinese (Taishō Volume 13, Number 418) by Paul Harrison, BDK English Tripitaka 25- II [Harrison(1998)은 http://lirs.ru/lib/sutra/Pratyutpanna _and_Surangama_Samadhi_Sutras,1998,BDK25.pdf에서 다운로드 받을 수 있다. 이 PDF에는 또한 BDK English Tripitaka 25-피이 포함되어 있는데, 이는 John $\mathrm{McRae}$ 가 구마라집(Kumārajīva)의『首楞嚴三昧經』(Sūrangamasamādhisūtra)의 중국어 번역을 영어로 번역한 것이다. 
서 200페이지가 넘는 분량을 $1978(\mathrm{~b})$ 의 비판적 편집본에 대한 영어 번 역과 이에 대한 주석에 할애하고 있다. 그리고 부록에서 명확하게 밝 히듯이 티벳본에 대한 그의 번역이 결국은 Lokakșema에 의해 번역된 난해한 『반주삼매경』(T. 418) 등을 연구하는 기반이 된다는 점을 고려 할 때, 『반주삼매경』(T. 418)을 영역한 1998년 저술은 『반주삼매경』에 관한 한 'Lokakșema 프로젝트'의 완결판이라고 할 수 있다.3)

우리가 여기서 살펴보아야 할 책(1990)은 크게 서론 - 본론 - 부록으 로 구성되어 있다.

서론: I. 문헌의 개괄

ㅍ. PraS*의 내용과 역사적 중요성

III. PraS의 구조

IV. 영역에 대한 소개

본론: 티벳본 PraS에 대한 주해가 달린 영어번역

부록 $\mathrm{A}$ : 중국에서 $\mathrm{PraS}$ 의 문헌적 역사에 관한 몇몇 소견

$\mathrm{B}$ : 산스크리트 PraS 단편에 대한 비판적 편집과 영역

$\mathrm{C}$ : 티벳 PraS 문헌에 대한 수정(correction)과 교정(emendation)

$\mathrm{D}$ : 어휘주해(glossary)

*PraS는 Pratyutpanna-Buddha-Sammmukhāvasthita-Samādhi-Sūtra의 약호.

우선 이 중에서 본론은 오랜 시간에 걸친 저자의 노력이 드러나는

3) 물론 1998년의 저술은 앞선 두 저술[1978(b)와 1990]과 달리 각주가 전혀 없는 등 ‘학자적 작업’이 보이지 않지만, 적어도 1990 의 저술을 읽고 이해하기 위해서는 반드시 참고해야만 한다는 점에는 의심의 여지가 없다. 
이 책의 중심이라는 것은 반복할 필요가 없을 것이다. 그렇지만 이 책 을 읽으면서 평자 개인의 관심을 끌었던 부분은 부록 $\mathrm{A}$ 였다. 부록 $\mathrm{A}$ 는 이러한 티벳역에 대한 번역을 기반으로 어떠한 성과를 이루어낼 수 있 는 가를 직접적으로 보여준 부분으로서 해리슨은 본론 다음으로 가장 많은 70페이지 가량을 여기에 할애하고 있다.

이제 각각의 소제목 안에 어떤 내용이 서술되어 있는가를 살펴보자.

서론 I 문헌의 개괄에는 활용할 수 있는 PraS의 문헌에 대한 정보 가 담겨 있다. 우선 PraS의 산스크리트 텍스트는 한 폴리오(folio)만이 남아있는 사본의 단편만이 있으며, 티벳역은 Kanjur의 다섯 판본 (Delge, Narthang, Peking, Lhasa, Stog Palace)이, 중국 번역은 4종 ${ }^{『}$ 大方等大集經賢護分』(T. 416), 『般舟三昧經』1권본(T. 417)『般舟三昧 經』3권본(T. 418)『拔陂菩隡經』(T. 419)]이 남아서 활용 가능함을 밝 히고 있다.

서론 $\Pi$ 에서는 우선 PraS의 내용을 다루고 있는데, 이 내용은 이미 저자의 1978(a)년 논문4)에서 자세히 다루어졌기 때문에 다만 요약의 형식을 취하고 있다. 저자에 따르면 PraS의 내용은 (1) 공[성]을 주창 함(Sūnyavādin), (2) 새로운 사상에 대한 계시(revelation)와 선전 (propagation)에 관련된 개념들, (3) 보살의 윤리로 구성되어 있다. (1) 을 설명하자면, 불수념(Buddhānusmṛti)의 대승적 형태인 '현재의 부 처님들을 직접적으로 조우하는 삼매'가 암시하듯이 정토의 수행과 밀 접한 관련이 있는 것이 사실이고, 유가행파의 유심(唯心: cittamātratā) 사상도 나타나지만 이 경전의 핵심은 바로 반야경전 계통의 공성 혹은 모든 법의 실체가 없음(dharmanairātmya)의 강조에 있다는 점이다. PraS에서 수행자는 현재의 부처님들과 직접적으로 조우하는 삼매에

4) 1978(a) "Buddhānusmṛti in the Pratyutpanna-buddha-saṃmukhāvasthitasamādhi-sūtra", Journal of Indian Philosophy 6: 35-57. 
서 겪은 그 자신의 경험을 꿈속의 사물 혹은 관상화된(visualized) 부 정관의 대상과 비교함으로써 사물의 비실재성을 깨달은 후 -어떠한 특별한 언급 없이- 이것을 외계 사물 모두에 일반화하는 과정을 겪는 다. (2)는 모든 현상이 실체가 없다는 점에서 동일하다는 관점아래, '현 재의 부처님들을 직접적으로 조우하는 삼매'가 행하는 역할이다. 실제 로 이 삼매에서 수행자는 단순히 부처님들과 직접 대면하는 것만 아니 라 부처님들의 가르침을 직접 들을 수 있다. 이러한 삼매의 특징은 대 승경전의 찬술을 합법적으로 정당화시키는 역할 만이 아니라 몇몇 대 승 경전이 이러한 삼매 경험에 고무 받아 찬술해졌을 가능성을 암시한 다. 이와 관련한 해리슨의 한 가지 독특한 해석은 PraS에서 bahuśruta (多聞者)는 명상수행의 문맥에서 대승의 가르침을 듣고 암기하고 대승 으로 전향한 사람들을, dharmabhānaka(說法者)는 이러한 bahuśruta의 능동적 측면에 맞춘 대승의 가르침을 전파하는 사람들을 나타낸 것이 라고 본 것이다. (3)은 PraS에서도 다른 대승경전들과 마찬가지로 재 가신자의 역할을 인정하지만 출가수행을 강력히 권고한다는 점, 불탑 숭배 등과 관련된 윤리를 말한다. 서론 $\Pi$ 의 두 번째는 PraS의 역사적 중요성에 관해 다루고 있다. 간략히 정리하자면, 인도 내에서 PraS가 강력한 전통이라는 증거가 없으며 -아마도 중앙아시아 지역에서 유 행하였을 것이며- 중국 등의 동아시아 전통에서는 혜원의 예에서 찾 아 볼 수 있듯이 아미타불 신앙, 극락왕생의 기원(祈願)과 결합하여 매 우 중요시되었다.

서론 III PraS의 구조에서는 티벳역의 26장 각각에 어떠한 내용이 기술되어 있는가를 다루고 있다. 해리슨은 이 26장의 내용을 크게 셋 으로 다시 요약하는데, (1) nidāna(因緣) : 이 경전의 가르침 이전, 가르 침의 과정 중 그리고 그 이후에 일어날 사건의 기술, (2) 경전의 가르침 을 선전 혹은 선양하려는 목적을 지닌 부분, (3) 명상에 대한 가르침을 
포함한 이 문헌의 실제적인 메시지가 그것이다.

서론 IV 영역에 대한 소개는 어떠한 태도와 원칙에 입각하여 티벳본 PraS를 번역하였는가에 관해 설명하고 있다. 또한 해리슨은 "무엇 때 문에 Lokakșema 프로젝트에서 Lokakșema가 179년에 번역한 반주삼 매경(해리슨에 따르면 T. 418만이 이에 해당함)이 아니라 800 C. E.의 티벳역을 번역하였는가"에 답하고 있다. 즉 그는 산스크리트 본이 없 기 때문에 가장 번역하기에 쉬운 티벳역을 활용함으로써 기나긴 역사 의 한 점에 있는 PraS에 접근할 수 있는 가장 확실한 길이기 때문이라 고 답하고 있다. 앞서 이미 언급했다시피 해리슨의 1998년의 저술은 이러한 티벳역에 대한 번역을 기초로 하여 난해하고 그 뜻을 파악하기 힘든 『반주삼매경』(T. 418)을 번역하였다. 이러한 방법론은 산스크리 트본에 대한 이해를 기반으로 중국 역경사 초기에 번역된 대승 경전을 비판적으로 편집하여 번역하거나[Zaccheti(2005)] 새로운 비판적인 교 정본[Karashima(2011)]을 출판하는 최근의 조류와 더불어5) 초기에 번 역된 난해한 문헌들을 번역하고 이해하기 위해서는 산스크리트와 티 벳어에 대한 언어적 역량이 반드시 필요하다는 점을 시사해주고 있다. 본론은 이미 언급하였다시피 해리슨이 편집한 티벳본[1978(b)]에 대 한 영어 번역으로서 티벳본의 분류에 따라 총 26장(Chapter)으로 구성 되어 있다. 각주에는 티벳역과 커다란 차이가 나거나 중요한 한역들의 이체자와 티벳역의 의미를 명확하게 할 수 있는 한역을 번역하여 실고 있다. 그리고 티벳본과 나머지 한역들의 위치정보의 비교에 관해서는

5) Zaccheti, Stefano(2005), In Praise of the Light : a critical synoptic edition with an annotated translation of chapters 1-3 of Dharmaraksa's Guang zan jing, being the earliest Chinese translation of the larger Prajñāpāramitā, Tokyo : International Research Institute for the Advanced Buddhology.

Karashima, Seishi(2011), A critical edition of Lokakșema's translation of the Aștasāhasrikā Prajñāpāramitā, Tokyo : International Research Institute for Advanced Buddhology, Soka University. 
1978년(b)의 부록 A와 B (pp. 225-239)를 참조하면 쉽게 찾을 수 있다. 번역을 직접적으로 참조하고자 하는 독자는 앞서 언급한 1978(b)년과 1998년의 저술만이 아니라 이 책의 부록 C 또한 참조하기를 권한다. 부록 C“『반주삼매경』티벳 문헌에 대한 수정과 교정’은 평자가 이 책 을 읽으면서 해리슨의 학자적 양심과 그 근면성에 감동을 받은 부분이 다. 이는 10여 년 전 출판된 1978(b)에 이후의 연구 성과를 반영한 교 정으로서, 학자라면 누구나 해야 하지만 실제로 행해진 예를 찾아보기 힘든 작업이다. 해리슨의 1978(b)년의 저술은 티벳 Kanjur의 Derge, Narthang, Peking, Lhasa 판본을 대조한 '비판적 편집본’이다. 이 이후 의 연구 성과에 따르면, 이러한 4종의 Kanjur 판본들은 14 세기 중반부 터 시작된 Kanjur의 개정판으로부터 유래한 동쪽 (Tshal pa) 전통에 전적으로 의지하기 때문에 14 세기의 고(古) Narthang 본으로 귀속되 는 서쪽(Them spangs ma) 전통의 읽기(reading)를 반영하지 못한 절 름발이 편집이다. 해리슨은 이 책에서 1978년의 책에서 반영하지 못했 던 서쪽 전통의 읽기를 라닥에 있는 Stog Palace에 보관되어 있는 사 본을 참조하여 보완하여 이를 부록 C에 실었다. 따라서 해리슨이 편집 한 티벳 문헌을 참조하고자 하는 독자라면 반드시 이후의 교정과 정정 을 염두에 두어야 할 것이다.

부록 $\mathrm{A}$ ‘중국에서 PraS의 문헌적 역사에 관한 몇몇 소견'은 평자가 이해하는 한에 있어서 이 책의 백미(白眉)이다. 부록 A는 다시 10개의 소제목으로 나뉘는데 이 중 $\mathrm{IV}$ “반주삼매경』3권(T. 418)의 두 개정판 (Redactions)'과 V “반주삼매경』3권의 저자'와 $\mathrm{VI}$ “반주삼매경』1권 (T. 416)'은 산스크리트 사본의 편집에서 주로 볼 수 있는 계통도 (family tree)를 사용하여 문헌들 사이의 관계를 추적하는 매우 흥미진 지한 부분이다. 지면 관계상 그 과정을 모두 설명할 수 없고 다만 결론 만을 요약할 것이기 때문에, 관심이 있는 독자라면 부록 $\mathrm{A}$ 에 특별한 
주의를 기울여서 읽기를 권한다.

앞서 서론 I 문헌의 개괄에서 살펴보았듯이 산스크리트 더욱 정확 히는 인도 문헌(Indic text)에 대한 중국어 번역(한역)은 4종-물론 티 벳본을 비롯한 모든 한역들은 서로 다른 버전의 인도 문헌에 기반하였 다 이 있다. 이 4종의 한역 중 『현호경』(T. 416)은 Jñānagupta(闇那倔 多)에 의해서 594 595년에, 『발피보살경」(T. 419)는 번역자 미상의 280 년 이전의 번역이라는 점에는 논의의 여지가 없다. 그렇지만 전통 에 따르면 『반주삼매경』이라는 동일한 제명을 가지고 있는 T. 418(3권 본)과 T. 419(1권본)은 모두 Lokakssema에게 귀속되고 있다. 학자들은 이러한 전통을 따르거나 혹은 T. 419(1권본)을 Lokakșema에게, T. 418(3권본)을 Dharmarakșa(筑法護)에게 귀속시킨다. 해리슨은 이러한 이전 연구 결과에 의구심을 표하면서 사꾸라베 하지베가 적절히 보여 주었던 T. 418(3권본)에 두 가지 버전 즉 신수대장경이 기반하고 있는 고려대장경본(K)과 중국의 송본 · 원본 - 명본(SYM)이 있다는 사실에 주목하였다. 해리슨에 따르면 티벳본의 1-6장에 해당하는 K와 SYM 사이에는 전자가 게송(gāthā)을 산문으로 후자가 운문으로 번역하고, 전자의 nidana(因緣)가 한 줄의 요약인 반면 후자의 그것은 상세한 즉 완전히 발전된 형태를 보여주는 등의 간극이 있다. 이에 반하여 티벳 본의 7-26장에 해당하는 두 버전은 차이를 보이지 않는다. 해리슨은 양자 중 어떠한 버전이 Lokakșema에게 귀속되는 것인가를 고찰하기 위하여 Lokakșema의 저작을 구분할 수 있는 시금석(touchstone)인 『 도행반야경』을 이용하여 양자의 전문용어(technical term) 76 개를 비 교하였다. 그 결과 티벳본의 1-6장에 해당하는 $K$ 와 『도행반야경』이 사용한 전문용어들이 공통된 반면 $\mathrm{SYM}$ 의 용어는 『도행반야경』의 그 것과 차이를 보이는 것을 발견하였다. 이러한 사실에 기초하여 그는 티벳본의 1-6장에 해당하는 K를 Redaction A로, SYM(티벳본 7-26장 
에 해당하는 K)을 Redaction B로 명명하고, 전자를 Lokakșema에 귀 속시키고 후자를 아마도 Lokakșema 학파의 산스크리트 사본에 접근 가능했던 사람들로 귀속시킨다. 다시 말하자면, 3세기경 Lokakșema의 번역이 유행하였을 때, PraS의 산스크리트 사본을 접했던 사람들이 Redaction A라고 부르는 Lokakșema의 번역을 가지고 산문 게송 ( $g \bar{a}$ thā)들을 운문으로 바꾸었으며, 이와 동시에 Lokakșema가 습관적 으로 줄인 nidāna를 완전한 번역으로 대치하는 등의 산문 또한 살짝 개정해서 Redaction B가 생겨났다는 것이다.

해리슨은 앞서 설한 전통과는 달리 『반주삼매경』1권본(T. 417)을 Lokakșema에 귀속시키지 않는다. 왜냐하면 T. 417에서 사용한 전문 용어가 Lokakșema에 귀속되는 Redaction A가 아니라 Redaction B와 일치한다는 점과 도저히 Lokakșema에 귀속할 수 없는 중대한 내용의 변화가 일어나기 때문에, 작자미상의 Redaction B에 대한 축약본이라 고 결론 내리고 있다. 내용의 변화에 대한 한 가지 예를 들면 '반복해서 아미타불을 마음속에 떠올리는 것(念)'[Redaction A]이라는 관상(觀想 : visualization)에서 ‘아미타불의 이름을 부르는 것’(T. 417)의 칭명(稱 名)으로 바뀐 것은 도저히 동일한 번역자인 Lokakșema로부터 나올 수 없다는 것이다.6)

해리슨은 이러한 그의 가설을 뒷받침하기 위해『승우록』등의 목록 을 살펴보지만, 목록은 오히려 T. 419(1권본)을 Lokakșema에게, T. 418(3권본)을 Dharmarakșa(箨法護)에게 귀속시키는 학자들의 주장을 뒷받침해준다. 해리슨은 이러한 외적 증거보다는 자신이 발견한 내적 증거 즉, 전문 용어의 차이 등을 우위에 두어 다음과 같은 가설을 세우 고 있다.

6) 爾時阿彌陀佛 語是菩薩言 欲來生我國者 常念我數數 (T. 418, 905b10-12) $\rightarrow$ 阿彌陀佛 報言 欲來生者當念我名（T. 417, 899a29-b01）

폴 해리슨의『현재의 부처님들과 직접 조우하는 삼매』에 대한 리뷰 289 
(1) 179 C. E. : Lokakșema가 2(혹은 후에 3)권 16품으로 이루어진 PraS를 번역(=Redaction A).

(2) 208 C. E. : Lokakșema 학파의 구성원들에 의해 Redaction A의 교정본인 Redaction $\mathrm{B}$ 가 만들어짐.

(3) 3세기: 『발피보살경』(T. 419)이 번역됨.

(4) 4혹은 5세기: Redaction B의 축약본인 T. 417이 만들어져 Lokakșema의 번역으로 귀속되고, 반면에 Redaction $\mathrm{B}$ 는 Dharmarakșa로 귀속됨 (7세기경 T. 417은 시야에서 사라졌다가 고려 대장경에서 나타남).

(5) 595 C. E: 인도 승려인 Jñānagupta와 Dharmagupta가 『현호경』 (T. 416)을 번역.

(6) 8세기까지 PraS의 세 가지 버전 (Redaction B, 『현호경』, 『발피 보살경』)이 중국에서 나타남.

(7) 9세기 초 티벳어로 번역됨.

부록 $\mathrm{B}$ 『반주삼매경』의 산스크리트 사본 단편은 해리슨이 20세기 초 중앙아시아에서 발견되고 현재 런던 India Office Library에서 보관 하고 있는 'Hoernle No. 143, S.A.3'의 한 폴리오(folio)를 재편집한 것 이다. 해리슨은 이미 Thomas에 의해서 편집되어 1916년 발표된 편집 본보다 좀 더 개선된 읽기(improved readings)를 제공하였는데, 이는 선명한 사본의 사진본과 산스크리트 운율에 대한 고려, 티벳역, 한역들 의 도움으로 좀 더 많은 부분을 복원했기 때문이다. 또한 그는 단지 산 스크리트 사본의 편집에 그치지 않고 이에 대한 영어 번역과 이에 상 응하는 T. 416(594-595)과 T. 418(179)의 부분에 대한 영역도 실었다. 이러한 과정을 통하여 그는 Jñānagupta에 의해 594 595년 번역된 『 현호경』(T. 416)이 산스크리트 단편의 내용과 가장 일치함을 밝혔다. 
그리고『현호경』의 내용이 산스크리트 사본의 그것보다 자세히 기술 되었다는 측면에서 사본의 단편이 『현호경』보다 오래된 형태를 반영 하고 있는 것이 아닐까라고 조심스럽게 추정한다.7)

부록 $\mathrm{D}$ 의 어휘주해는 PraS에서 300 개 정도의 인명(人名)과 전문 용 어와 단어들을 뽑아 산스크리트의 알파벳 순서대로 정리한 것으로, 산 스크리트 - 영어번역-산스크리트에 상응하는 티벳어-찾아보기(Index) 의 순으로 이루어져 있다.

이상이 해리슨의 1990 년도 저술의 내용이다. 본 평자의 리뷰는 비판 적(critical)보다는 그 내용을 소개하는 선에서 그치고 있는 것이 사실 이다.8) 실제로 본 책에는 해리슨의 산스크리트와 티벳어에 대한 이해 수준과 중국어(한역)에 대한 수준이 조금은 다르다는 점- 물론 이것은 대부분 초기에 번역된 난해한 『반주삼매경』으로부터 기인한다-과 그 의 Pras 텍스트 전승에 대한 가설이 외적 증거에 의해 뒷받침되지 못 했다는 점이 있는 것도 사실이다. 그럼에도 불구하고 20년 이상이 지 난 이 저술은 우리에게 많은 점들을 시사해준다. 이러한 점들 중 하나 는 초기의 한역, 더욱 정확하게는 번역 문헌을 다루기 위해서는 고전 중국어뿐만 아니라 산스크리트와 티벳어에 대한 지식이, 좀 더 나아가 서는 Zaccheti(2005)와 Karashima(2011)가 보여주듯이 다양한 언어로 쓰인 사본들에 대한 접근이 점점 요구된다는 점이다.

마지막으로 다른 학자들에 의해 연구된 삼매 관련 저술-주로 대승

7) 그렇지만, ‘이 사본 자체는 Jñānagupta가 『현호경』을 번역한 이후에 쓰였을 수도 있다’라고 하여, paleography(고서체)의 확증이 없는 단순히 내용이 T. 416보다 자세하다는 단편적인 이유만으로 사본 단편의 연대기를 Jñānagupta가『현호경』을 번역한 594년 이전으로 소급하는 초보적인 실수를 피하고 있다.

8) Sakurabe Hajime는 이전의 일본에서 행해졌던 연구 성과를 기반으로 한 좀 더 비판적인 서평을 쓰고 있다. 이에 관해서는 『佛敉學セミナ一』53号(1991), pp. 48-52 를 참고하시오. 특히 경전의 성립연대(p. 50)와 추정에 기반한 자의적인 환범(p. 51)은 경청할 만한 가치가 있다고 생각된다. 
불교와 관련된-들을 소개하는 것으로 이 글을 마치고자 한다. 우선 본 리뷰의 주제인 반주삼매와 그 기원인 불수념에 관한 연구로는 Harrison[1978(a): 각주 4 참고할 것]이 있고, 반주삼매와 유사한 중국 기원의 관상 삼매에 관한 연구로는 Yamabe(1999)가 있을 것이다.

대승경전을 한 번이라도 읽어 본 사람들이라면 누구나 경전의 첫 머 리에 다양한 수의 삼매가 나열되어 있다는 사실을 알 수 있다. 그렇지 만 그 텍스트 혹은 관련된 다른 텍스트를 살펴보아도 대부분의 삼매들 에게는 실제로 어떻게 행하는 지와 그 상태에 관한 설명이 없기 때문 에, 과연 이것이 실제로 행하는 삼매인가 다만 명칭만이 존재하는가에 관한 의구심을 누구나가 한 번쯤은 품을 만하다. Samāadhirājasūtra ${ }^{\mathbb{P}}$ 삼매왕경』)의 전문가인 Skilton의 2002년 논문은 이러한 의구심을 잠 재울 수 있는 뛰어난 저술이다. Lamotte도 Súramgamasamāadhisütra (『수능엄삼매경』)의 번역에서 성문과 대승의 삼매를 대비하여 이러한 의구심에 대한 답을 제시하고자 하였다[Lamotte(trans by Sara Boin-WeBB: 2003) pp. 11-38]. (또한 『수능엄삼매경』에 관해서는 각 주 2에서 소개한 John McRae의 번역이 있다.) 마지막으로 반야경류의 수행과 밀접한 삼삼매(공[성] - 무상 - 무원삼매)에 관해서는 부족하고 많은 보완이 필요하지만 이영진(2008)이 어느 정도 윤곽을 드러낼 수 있다고 생각한다.9)

9) (1) Nobuyoshi, Yamabe(1999), The Sūtra on the Ocean-Like Samadhi of the Visualization of the Buddha: The interfusion of the Chinese and Indian cultures in Central Asia as reflected in a fifth century apocryphal sūtra, Yale University.; (2) Skilton, Andrew T (2002), "State or statement? Samāahi in some early Mahāyāna Sūtras," The Eastern Buddhist 34.2 : 51-93.; (3) Étienne Lamotte(trans by Sara Boin-WeBB: 2003), Sūramgamasamādhisūtra: The Concentration of Heroic Progress An early Mahāyāna Buddhist Scritpture - translated and Annotated by Étienne Lamotte, English translation by Sara Boin-Webb, Delhi: Motilal Banarsidass Publisher; (4) 이영진(2008), 『공성기술의 두 형태』, 동국대학교 박사학 위논문. 